
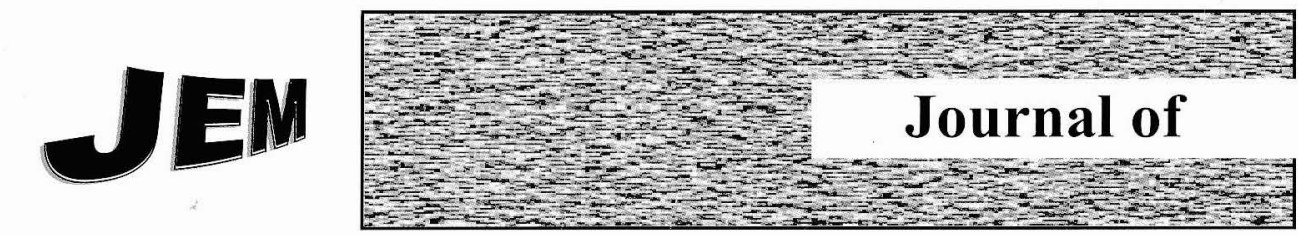

EDucational Management

A Bi-annual Publication of

THE INSTITUTE FOR EDUCATIONAL PLANNING AND ADMINISTRATION

(IEPA)

University of Cape Coast, Ghana

ISSN 0855 - $3343 \quad$ Vol. $6 \quad$ Nov. 2012 


\section{Curbing Examination Malpractices in Ghanaian Tertiary Institutions: The Case of Takoradi Polytechnic}

\section{Maame Afua Nkrumah \\ Samuel Obeng Apori}

\begin{abstract}
Examination malpractice occurs at all levels of education. The situation is not different at Takoradi Polytechnic. Recent media reports indicate that examination malpractices in its various forms are on the increase in Tertiary Institutions in Ghana. This has raised serious concerns among stakeholders in education considering the fact that the buzz word today is quality education. This research was set out to investigate the rate, types/forms, causes, punishments, effects and most important how the ion of the menace can be curbed at the Polytechnic in particular; and others Polytechnic at large.
\end{abstract}

Presented in this report are the results of the study at Takoradi Polytechnic and its implication for other tertiary institutions in Ghana. The study revealed that examination malpractice occurs regularly at Takoradi Polytechnic mostly because of problems with the provision of Guidance and Counselling Services to students and social activities on campus. The problem has become a habit for some students and has made the interpretation of feedback from assessment unrealistic to assessors. Most importantly, how the problem has effective been managed is also discussed in this report. The results of the research form a basis for further discussions on examination malpractice and this opens a number of fields for further research and debate.

\section{Introduction}

The main objective of Tertiary education in Ghana is to furnish students with the requisite knowledge and skill for employment and national development. This requires that students pass periodic assessment and evaluation at all levels of their education. Students in their bid to do so engage in all sorts of misconducts including examination malpractices. Examination malpractices in its various forms occur in both internal and external examinations at Takoradi Polytechnic. To make matters worse, it is not only students that are involved, parents, teachers and examination officials, all collude with students to perpetrate this misconduct. The involvement of the above mentioned agents makes it even more difficult to combat the problem. In fact the menace was almost a ritual at the Polytechnic.

\section{Purpose of the Study}

Considering the persistence of examination malpractices at Takoradi Polytechnic and other Tertiary Institutions in Ghana, and the fact that the buzz word today is quality education; it was worthwhile to investigate the problem of examination malpractice at Takoradi Polytechnic and its management. The following were investigated: 
- The rate of examination malpractices at Takoradi Polytechnic;

- Why people engage in examination malpractices and;

- How the menace has been controlled at the Polytechnic.

\section{Research Problem}

Although examinations are not the only instruments for assessing and evaluating knowledge and skills, it has emerged as the major established yardstick for the assessment of students (Adomako, 2005). According to the National Board for Professional and Technician Examination's (NABPTEX) Institutional Guidelines for Polytechnics (1994), the purpose of students' assessment is to ensure that students can demonstrate that they have fulfilled the objective of the programme of study and have achieved the standard required for the award of Higher National Diploma (HND). In doing this, students are continuously assessed in quizzes; take home assignments, mid-semester examinations and end of semester examination. The Guidelines further states that for a yearly academic progression for students, an average Cumulative Grade Point of not less than 1.5 is required. A student who fails four or more courses at the end of any semester will be withdrawn. These and many other requirements make examination malpractice more or less very attractive to students.

The persistence of the menace at the Polytechnic has in times past impelled the Academic Board of the Polytechnic to set up a four member
Committee to look into the problem and make recommendations (June, 2006). Based on the recommendations of the Committee, several measures were put in place to control the menace. It has been the fervent desire of the Polytechnic as it were to record incidence-free examinations in the very near future; even though the problem is very human. From this background, the research was carried out with the object finding out which measures best work for the Institution in controlling the menace, so that other Tertiary Institutions in Ghana and elsewhere can benefit from the experience of the Institution.

\section{Research Questions}

1. What is the rate of examination malpractice at Takoradi Polytechnic?

2. What factors are mostly responsible for examination malpractices?

3. What preventive measures are working for the Polytechnic?

\section{Literature Review}

\section{What Is Examination Malpractice?}

Examination malpractice is any act of omission or commission, which compromises the validity and integrity of any examination (Ministry of Education, Benue State, 2001). Malpractice refers to counter practice that is against ethics of examination. Such practices also include illegality, that is, an act or any act(s) of misconduct such as leakage, impersonation, writing on hidden part(s) of wares, encoding/decoding of 
the fingers for objectives tests, exchanges of question papers and answer booklets; committed before, during or after the examination by either the students taking the examination or by officials assigned to administer, evaluate or measure students' performance.

The NAPTEX Student Guide (1994) lists among other things the following forms of examination malpractices: Copying during examinations; writing on thighs, handkerchiefs, calculators, socks and desks; illegal prior possession, knowledge or use of examination papers; leakage of examination papers; Impersonation; communication verbally or in writing; insulting/assaulting examination officials before, during and after examinations; fraudulently replacing the original script of a candidate; and making unlawful changes on the original script of any candidate.

Takoradi Polytechnic also indicates the following as forms of examination malpractices; in addition to the rules and regulations from NAPTEX: possession of foreign material (books, paper, sketches, programmable calculator, etc); substituting worked scripts during/after examination; refusing to submit worked scripts; tearing part of question paper/answer booklet; taking question/answer booklet outside the examination hall; collusion (Unauthorized passing of information between candidates, usually by exchanging notes or scripts/colluding with teachers or invigilators for assistance in answering questions); putting on of attire that gives room for suspicion (caps, hat etc.); Giraffing; bringing mobile phones to the examination hall; Communicating (verbally or by the use of gestures) with other candidates; and the use of tip-ex.

The NABPTEX Student Guide (1994) stipulates the following punishments for culprits:

disqualification from taking the examination and the cancellation of results; prohibition from taking any examination conducted by the Board for a period not less than two years immediately following the breach; liability on conviction to a fine not less than fifty thousand old Ghana Cedis and not exceeding one million old Ghana Cedis or imprisonment for a term not more than one year or may be liable to both. The Takoradi Polytechnic Students' Handbook (2006) further stated that a student found to be involved in examination malpractice shall be dismissed from the Polytechnic. In addition, the offense may be communicated to other Tertiary Institutions and relevant bodies and agencies. However, the final decision to dismiss a student rests on the Rector of the Polytechnic (Statutes of Takoradi Polytechnic, 1995).

Examination malpractice has grave consequences on both individuals and Institutions of learning, communities and the country as a whole. Dismissal, rustication, loss of position and self confidence as a result of examination malpractice has brought much embarrassment and suffering to individuals, families and communities (Okwu, 2006). Those who are not caught and punished may be expelled after gaining admission for further studies. If employed, they may not be able to perform to set out standards hence may eventually lose their jobs. 
How Can the Menace be Curbed/Managed

Okwu, (2006) recommended that in order to curb the problem of examination malpractice in Tertiary Institutions, the admission of students should not be based only on previous results or certificates but also on performance in entrance examinations. Also those found guilty of examination malpractice should be punished severely. Culprits of examination malpractice should not just be expelled from the institutions but should be tried and jailed to serve as deterrent to others.

\section{Methodology}

The research sought to investigate the rate and types/forms of examination malpractices, in addition to what control measures are working for the Takoradi Polytechnic. The data collected concentrated on the above mentioned issues. Basically, data was taken through the use of the five point (Likert scale) semi-structured questionnaires and an interview guide. Student's records and administrative documents were also studied to obtain information on rate, forms and consequences of examination malpractices at the polytechnic. The interview guide was used to obtain information on the rate, reasons, and consequences of examination malpractices in the polytechnic and how management is dealing with the problem. The semistructured questionnaires sought information on similar issues but from students and staff.

\section{Selection of Respondents}

The research involved a sample size of 468: 3 Disciplinary Committee (DC) Members (Vice Rector, Registrar and the President of the Student' Representative Council (SRC); 108 Lecturers; and 357 students from the four School of the Polytechnic: Applied Art, Applied Science, Business and Management Studies, and Engineering. There were 159 females and 309 males. The case study was conducted at Takoradi Polytechnic because examination malpractice occurs regularly at the Polytechnic. Also from the DC's reports on examination malpractices (2005-2007), examination malpractice occur in all the four Schools, hence the selection of respondents from all the Schools of the Polytechnic. The DC Members were chosen purposively because of the role they play in dealing with cases of alleged examination malpractice in the Polytechnic. The sample size was based on Krejcie \& Morgan's (1970) recommendation on sample size selection under a confidence interval of $95 \%$ for a specified population size (students and staff strength). The data was analysed using the statistical package of social sciences (SPSS).

\section{Results}

The demographics of the respondents are presented on Table 1 below: 
Table 1: Profile of Respondents

\begin{tabular}{lrrr}
\hline Respondent & Female & Maie & Total \\
\hline Students & 122 & 235 & 357 \\
Staff & 37 & 71 & 108 \\
Vice Rector & 0 & 1 & 1 \\
Registrar & 0 & 1 & 1 \\
SRC President & 0 & 1 & 1 \\
Total & 159 & $\mathbf{3 0 9}$ & $\mathbf{4 6 8}$ \\
\hline
\end{tabular}

Source: Field Survey, 2008.

The results of the study are presented according to the three main aspects of the research questions as set out as below:

- The rate of examination malpractices;

- Causes of examination malpractice;

- Control/prevention measures that have worked,

A. The Rate/Problem of Examination Malpractice at Takoradi Polytechnic:
Many techniques have been employed by students to cheat in examinations at the Polytechnic. On record however, the following forms were known: possession of foreign materials ( $54 \%$ ) writings on papers, calculators, belts, edges of shirt sleeves, handkerchiefs, thighs, palms etc; exchange of answer booklets $(11 \%)$; possession and copying from slabs ( $9 \%$ each) among others (Table 2).

Table 2: Techniques Employed By Students to Cheat (2004/5-2007/8)

\begin{tabular}{lr}
\hline Malpractice & Percentage \\
\hline Possession of foreign material (on e.g. calculators, papers, shoes.) & 54.3 \\
Exchange of examination papers/scripts & 11.2 \\
Possession of slabs with written information & 8.6 \\
Copying from foreign material & 8.6 \\
Possession of unanswered answer booklets & 8.6 \\
Possession of already answered answer booklet & 2.9 \\
Insubordination & 2.9 \\
Use of mobile phone during the examination & 2.9 \\
Total & $\mathbf{1 0 0 . 0}$ \\
\hline
\end{tabular}

Source: DC file, 2005/6 -2007/2008 academic year, with the exception of the 2004/2005 
From the interviews however, it became clear that there were other forms of examination malpractices off record. For instance, some Lecturers set the same examination questions for different groups of students writing the same paper at different times. Also, some students manage to have prior knowledge of examination questions either by buying, inducing staff with either money/materials/ kindness or by colluding with staff who are directly/indirectly involved with examinations. It was interesting to note that some students make nonsense of the vigilance of the Invigilator by using gestures that were meaningful only to the parties involved. There were few cases of impersonation; due to improper identification of students and insults/ threats on staff.

The Rate According to School, Sex and Year Group

According to reports of the Disciplinary Committee (DC) on examination malpractices (2005/6 $2007 / 2008$ academic years) the menace occurs regularly at the Polytechnic. The School of Business and Management Studies was the most hit for all the selected academic years $(54 \%)$. The School of Engineering (25\%), Applied Arts (16\%) and Applied Science (16\%) followed respectively with significant percentages.

\section{Table 3: Rate of Examination Malpractice at the School Level}

\begin{tabular}{|c|c|c|c|c|c|c|c|c|c|c|}
\hline \multirow[t]{2}{*}{ School } & \multicolumn{2}{|c|}{$2003 / 2004$} & \multicolumn{2}{|c|}{$2005 / 2006$} & \multicolumn{2}{|c|}{$2006 / 2007$} & \multicolumn{2}{|c|}{$2007 / 2008$} & \multirow[b]{2}{*}{ Total } & \multirow[b]{2}{*}{$\%$} \\
\hline & No & $\%$ & No & $\%$ & No & $\%$ & No & $\%$ & & \\
\hline Business & 10 & 66.7 & 11 & 73.3 & 13 & 44.8 & 13 & 46.4 & 47 & 54.1 \\
\hline Engineering & 5 & 33.3 & 1 & 6.7 & 7 & 24.1 & 9 & 32.1 & 22 & 25.1 \\
\hline Applied Art & 0 & 0 & 2 & 13.3 & 8 & 27.6 & 4 & 14.3 & 14 & 16.1 \\
\hline Applied Science & 0 & 0 & 1 & 6.7 & 1 & 3.4 & 2 & 7.1 & 4 & 4.7 \\
\hline Total & 15 & 100.0 & 15 & 100.0 & 29 & 100.0 & 28 & 100.0 & 87 & 100.0 \\
\hline
\end{tabular}

Source: DC file, 2005/6 -2007/2008 academic year, with the exception of the $2004 / 2005$.

The School of Engineering had the second highest number of students for $2003 / 2004$ (33\%), and 2007/2008 academic years $(32 \%)$ respectively. The School of Applied Arts had the second highest number of students alleged to have engaged in the menace for $2005 / 2006(13 \%)$ and $2006 / 2007$ $(27 \%)$ academic years respectively (Table 3).

The study indicated that generally males engage in examination malpractice more than females. For instance, for the 2003/2004 academic year, eleven out of the total number (15) of students alleged to have engaged in examination malpractice were males. During the 2005/2006 academic year, a total of 15 students were reported to have engaged in the menace. Out of this number, only one was a female. Considering the $2006 / 2007$ academic year, 27 out of the 29 students involved in examination malpractice were males. The situation was not different for the 2007/2008 academic year. Twenty-four out of the total number of students (28) were males with only 4 females from the Department of Catering and 
Hospitality Management (mostly students from the department are females). Table 4.

\section{Table 4: The Trend among Sexes and Year Group}

Consideration was further given to the occurrence of the menace with respect to each year group. In general terms, the first years were more prone to the canker $(80 \%, 80 \%, 27 \%$ and $43 \%)$ more than their other counterparts. The

\begin{tabular}{lrrrrrrrrrrrr}
\hline Year & $\begin{array}{r}03 / 04 \\
\%\end{array}$ & $\mathrm{M}$ & $\mathrm{F}$ & $\begin{array}{r}05 / 06 \\
\%\end{array}$ & $\mathrm{M}$ & $\mathrm{F}$ & $\begin{array}{r}06 / 07 \\
\%\end{array}$ & $\mathrm{M}$ & $\mathrm{F}$ & $\begin{array}{r}07 / 08 \\
\%\end{array}$ & $\mathrm{M}$ & $\mathrm{F}$ \\
& & & & & & & \\
\hline First & 80.0 & 6 & 2 & 80.0 & 8 & 0 & 27.6 & 15 & 2 & 42.9 & 13 & 1 \\
Second & 13.3 & 3 & 1 & 13.3 & 5 & 1 & 20.7 & 7 & 0 & 32.1 & 6 & 2 \\
Third & 6.7 & 2 & 1 & 6.7 & 1 & 0 & 51.7 & 5 & 0 & 25.0 & 5 & 1 \\
Total & 100.0 & 11 & 4 & 100.0 & 14 & 1 & 100.0 & 27 & 2 & 100.0 & 24 & 4 \\
\hline
\end{tabular}

$\mathbf{F}=$ female, $\mathbf{M}=$ male

Source: DC file, 2005/6 -2007/2008 academic years, with the exception of the 2004/2005

second years also fell victims but, second to the first years. For almost all the selected academic years, the second years had the second largest percentage of students $(13 \%, 13 \%$ and $32 \%$ ) with the exception of the 2006/2007 academic year (21\%). The final year students were not free from the offence. For instance, for the 2006/2007 academic years, most of the students involved in examination malpractices were final year students
$(52 \%)$. The specifics can be found on Table 4 above.

\section{Consequences of Examination} Malpractices at the Polytechnic

Records on the consequences of the menace at the polytechnic are shown on Table 5.

Table 5: Punishment for victims (2003/4-2007/8 academic years)

\begin{tabular}{lc}
\hline Punishment & Percentage \% \\
\hline Rustication & 37 \\
Dismissal of students & 32 \\
Cancellation of results & 17 \\
Warning & 10 \\
Bond of good behaviour & 4 \\
Withholding of certificate & 1 \\
Total & $\mathbf{1 0 0 . 0}$ \\
\hline
\end{tabular}

Source: DC file, 2005/6 -2007/2008 academic year, with the exception of the 2004/2005

Almost all coded offences go with one punishment or the other Available records indicated that $37 \%$ of those who fell victim to the menace during the selected years have been rusticated for one or more years; $32 \%$ have been dismissed; $17 \%$ have had their results cancelled; $4 \%$ have been warned or have signed a bond of good behaviour 
and $1 \%$ has had their certificated withheld. Imprisonment of staff, withdrawal of certificates and payment of a fine did not usually happen at the Polytechnic.

Examination malpractice may have heinous effects on the individual, family, educational Institution or Country. Examination malpractice tarnishes the image of an Institution $(28 \%)$ and questions the quality of education offered by the Institution and the entire Nation as a whole $(15 \%)$. It can also significantly reduce the academic standing of an Institution and society's respect for the Institution at large. It is worth mentioning that the menace makes one incompetent on the job (15\%). In such instances, individuals who are very competent on paper exhibit below standard competencies and low self confidence when it comes to the performance of a given job. In addition, when an individual passes well because of examination malpractice it becomes easy to reason that one does not need to learn hard to pass. Unfortunately, if this not checked may result in the habit of cheating $(10 \%)$. In cases of dismissal, the future of the culprit may be ruined ( $8 \%$ ). Furthermore, examination maipractice makes it difficult for assessors to realistically interpret feedback from students ( $7 \%$ ).

\section{Table 6: Effects of Examination Maipractice on Manpower Develop- ment}

\begin{tabular}{ll}
\hline Effects & Percentage \\
\hline Defames the image of the Institution & 28.0 \\
Makes one incompetent on the job & 14.8 \\
Creates a dent on the quality of the certificate & 14.8 \\
May become a habit & 10.3 \\
May ruin the future prospects of the culprit & 7.7 \\
Makes deductions from assessment unrealistic & 7.2 \\
Brings disgrace to the individual and family & 6.5 \\
Undermines the integrity of the one concerned & 3.9 \\
Depression/anxiety & 1.9 \\
Total & $\mathbf{1 0 0 . 0}$ \\
\hline
\end{tabular}

\section{Source: Field Survey, 2008}

It was also indicated that the menace occurs with much disgrace and disappointment to the individual, family and other acquaintances ( $7 \%$ ). There is not doubt that individuals involved in examination malpractices would have their integrity brought into question (4\%). Stress/depression $(2 \%)$ was normally experience by culprits. Usually, the culprit's heart begins to beat fast, anxiety and stress set in; and for those who can not stand the stress, depression or worse still, mental disturbances may occur. The details can be found on Table 6 .

From the interviews, it became clear that the menace has serious economic consequences. For instance in cases of dismissal, all monies and resources spent become an economic waste. The individual's future may be ruined in the sense that any future prospect of further education or employment may 
be diminished and this is of course, an economic cost to both family and the country. Another economic consequence mentioned was that, it is at a great opportunity cost that the DC Members meet on cases of examination malpractice. Of course, the Polytechnic pays the Committee members and time spent could have been invested in other profitable endeavors. Further, it was mentioned that in instances of rustication, extra fees (paid by guardians and tax payers) and time are spent in completing the programme.

\section{B. Causes of Examination Mal- practice}

It was obvious from the interviews that examination malpractice is a desperate measure taken by students. It was argued that the roots of the menace can be traced to pre-tertiary education where, students are classified and placed according to their performance in examination. At the tertiary level, only students with relatively best results are picked because of constraints on admission space. Further, academic progression and sometimes employment depend on performance in examinations. From this background, cheating in examinations seems very attractive to many. Furthermore, society (e.g. parents, teachers, etc.) places undue pressure on students to excel. Also space during examinations is a cause. Most classrooms at the Polytechnic double as examination halls. These classrooms are limited in space and so during examinations; students are crowded in the examination hall with few invigilators (some invigilators do not turn up) thereby creating a conducive environment for cheating.
The problem is further compounded by the fact that most of these rooms have no locks hence, students make use of the rooms even before examinations start.

Another cause mentioned was that, stated penalties for examination malpractices were not always adhered to. In addition, if students are not intentionally guided and counseled on issues such as choice of academic programmes/courses, good study habits, how to conduct themselves during examinations, the consequences of examination malpractice among others; they are likely to engage in examination malpractice. Also lack of research into the problem and how the problem can be curbed contributes to the occurrence of menace. The quality of the students admitted was also an important factor. Unqualified students tended to cheat more than their qualified counterparts since they may lack the academic strength needed to withstand the numerous academic exercises.

Many of the respondents indicated that generally, the break down of our moral values has resulted in various forms of corruption including examination malpractice (inducing/accepting money, kindness, bribe for undue help either by students/staff). It was also significant to note that some Lecturers do not follow the academic calendar for the semester. As a result, such Lecturers tend to load students with many learning materials at the end of the semester (sometimes two weeks to examinations), thereby providing only a short period of time for students to assimilate academic materials supposed to be learnt within a whole semester. Such attitudes on the part of 
Lecturers act as a motivating factor for slow learners to engage in examination malpractice.

These notwithstanding, the general trend in most Polytechnics where questions are set at the beginning/ middle of the semester irrespective of its coverage were another contributing factor. Also some students do not adequately prepare for examinations. Others bet their hopes on alleged receipt of examination questions; are just lazy; or are unable to properly manage their time especially due to engagement in leisure. Mass failure, threats of failure and discouraging comments by Lecturers (e.g. I will fail you, insults etc.) instigate students to cheat in order to 'put Lecturers to shame'. Surprisingly, some students/ staff attempt to help others by engaging in examination malpractice. It is also very important to note that some cases of the menace may occur accidentally or may be the result of wrong accusations.

Many of the respondents agreed that lack of self confidence, inadequate teaching and learning materials, stress/anxiety are contributing factors. Of much concern was the alleged existence of improper relationships between staff and students. Also existing rules and regulations were seen not to be deterrent enough to prevent staff and students from engaging in the menace. From the foregoing, it is clear that many factors are responsible for examination malpractice at the Polytechnic.

The research further deemed it important to find out the most influential factors and their effect on the sexes. The research revealed that self confidence, determination to pass, social activities, poor preparation by students, stress and anxiety among others were the most influential factors. However, the effect of these factors on the sexes was not the same. For instance, males and females differed when it came to factors such as: self confidence, determination to pass, social activities, preparation for examinations and laziness. Despite these differences, stress and anxiety, inadequate teaching and learning materials and the short period for revision, had the same effect on both males and females (Table 7).

\section{Table 7: Most Significant Causes of Examination Malpractice Among the Sexes}

\begin{tabular}{lcl}
\hline Factor & t-value at 95\% (2-tail) & Implication \\
\hline Self confidence & 0.920 & Significant difference \\
Determination to pass & 0.098 & Significant difference \\
Social activities & 0.601 & Significant difference \\
Inadequate preparation by students & 0.601 & Significant difference \\
Stress/anxiety & 0.044 & No significant difference \\
Inadequate T/L materials & 0.049 & No significant difference \\
Short period of revision & 0.049 & No significant difference \\
Laziness & 0.848 & Significant difference \\
\hline
\end{tabular}

Source: Field Survey, 2008. 


\section{Control/Prevention - Things That Work}

There are various measures that have been used to control examination malpractice at the Polytechnic. Guidance and Counselling services are provided for both student and staff but most importantly to students (29\%). Such services emphasize good study habits, preparations towards examinations and how to get the best out of the Polytechnic etc. Further, instances of examination malpractices (leakages) are promptly and properly investigated to the root of the problem $(13 \%)$.

To combat instances of examination malpractices as a result of fear of staff or failure, the nurturing of a cordial relationship between the students and staff has been encouraged through open fora involving students and staff and departmental counselors who regularly meet students to address their concerns $(12 \%)$. In addition to the provision of moderately adequate teaching and learning materials for hands on learning experiences for students $(11 \%)$ the Polytechnic has reduced the number of hands that handle examination materials $(11 \%)$. Also, examination materials are physically secured in a special room called 'strong room.' Of course, the enforcement of existing rules and regulations on examination malpractices to the latter irrespective of who is involved has gone a long way to reduce the menace $(6 \%)$. Another measure that has been very effective is the change from the lecture method of teaching employed by most lecturers to a student centered approach (6\%). Regular assessment of students was also one of the most effective ways of dealing with the problem ( $3 \%)$. These notwithstanding, ensuring proper sitting arrangements and the creation of an enabling environment for examinations in addition to proper invigilation during examinations were argued for. The specifics are on Table 8.

Table 8: Control and Prevention of Examination Malpractice

\begin{tabular}{lr}
\hline Control & Percentage \\
\hline Guidance and Counselling services & 28.7 \\
Effective investigations into allegations & 13.4 \\
Good teacher/student relationship & 11.9 \\
Provision of adequate T/L materials & 11.4 \\
Proper security of examination materials & 10.9 \\
Implementation of existing rules & 6.4 \\
Good teaching methods & 6.0 \\
Fair assessment & 5.5 \\
Regular assessment of students & 2.8 \\
Proper sitting arrangement & 2.0 \\
Creation of enabling environment & 1.0 \\
Total & $\mathbf{1 0 0 . 0}$ \\
\hline
\end{tabular}

Source: Field Survey, 2008 


\section{Discussions}

Even though the Polytechnic law (1992) from which Ghanaian Polytechnics derive their mission emphasizes the acquisition of practical knowledge and skills, almost all Polytechnic examinations have a high predominance of theory. The practical aspect constitutes only $30 \%$ of the total marks of the continuous assessment (theory $70 \%$ ). This undue emphasis on theory causes students who might be more practically oriented to experience inadequacies in themselves, leading them to engage in examination malpractice.

Almost every semester, there are rumors that examination questions have leaked. This is what Sahman et al., (1990) called examination leakage. According to the results of the study, a major cause of these leakages is improper security of examination materials. In fact, the questions pass through too many hands: Head of Department, Vice Rector and external examiners outside the Polytechnic for modulation before finally getting to students on the examination day. After modulation, the reserve is done. As such, tracing the source of an examination leakage has always been a challenge. Another challenge in this direction is that even though the Institution is willing to investigate such cases; getting the concerned people to testify with concrete evidence has always been a probiem. Hence the sources of such alleged leakages have mostly remained in the bud. In addition some staff members connected with examinations out of selfish motives (money, gift, kindness) give out questions to students. This is not strange because, according to Akinyode (2004) poverty has injected into almost all civil servants the virus called bribery.

Currently, the Polytechnic has problems with space during examination (most classrooms double as examination halls) as a result, during examinations students are crowded in the examination halls. Denga (1993) argued that examination malpractice is partly an environmental problem (crowded nature of the examination hall). Also according to Ward (1981); Murphy (1988) and Lamm, (1984) poor preparation for examination(s) often leads to examination malpractice. This view was shared by most of the respondents. It was asserted that some students bet their hopes on alleged receipt of examination questions; others out of poor time management due to social activities on campus; and sheer laziness do not adequately prepare for examinations. Under such circumstances, resorting to cheating becomes easier.

Sometimes students who engage in examination malpractices get away with it. To a very large extent, the social systems in Ghana coupled with political-undertones are partly responsible for this. In Ghana, the external family system encircles the Head of an Educational Institution too many relatives, many of whom 'should not be offendered' Hence, in instances of examination malpractices; relatives, together with superiors and Politicians pressurize responsible ones to dilute punishments for culprits. The leader, not wanting to incur the displeasure of others and especially those in higher authority, may give in to such demands. Such happenings are what 
Olaniyan, (2002) and Peter, 2002) called partly as political undertones. In the same line of thought but at a lower level, some colleagues come in strongly to plead for students who have wronged. Some even refuse to report students because of fear of displeasing others or because of social relationships.

\section{Conclusion}

The research showed that examination malpractice occurs regularly at Takoradi Polytechnic; in almost all examinations. The general trend is that, the menace is on the increase considering the selected academic years. Generally, the first years engaged in examination malpractice more than the second and third years. Further, males engaged in examination malpractice more than their female counterparts. On record the following forms of examination malpractices were known: possession of foreign material, exchange of examination scripts/papers, possession of slabs with written information, copying from a foreign material, possession of unanswered answer booklet, possession of already answered answer booklets, insubordination, impersonation, use of mobile phones and use of gestures meaningful to only the parties involved. Off record however, there were allegations of examination leakages. Some Lecturers also set the same examination questions for the same group of students writing at different times.

The research revealed that lack of self confidence, determination to pass by all means; uncontrolled social activities, laziness and poor preparation were the responsible factors at the
Polytechnic. However, there were significant differences between males and females when it came to how these factors influence examination malpractice. Other factors identified were stress and anxiety, short period of revision and inadequate teaching and learning materials. It is important to note that with the latter factors, there were no significant difference between males and females.

Examination malpractice at Takoradi Polytechnic and other Tertiary Institutions in Ghana and elsewhere can be controlled or prevented by providing Guidance and Counseling Services to both student and staff. The need to provide adequate teaching and learning materials, ensure proper invigilation, the existence of a cordial relationship between internal stakeholders, proper handling of examination materials and investigations into examination malpractices can not be over emphasized. There is also the need for regularly assessment of students. In a similar vein the proper sitting arrangement of students during examinations should be ensured. Regular research is also needed if the Polytechnic is to solve its own internal problems:

\section{Implications}

The results of the research have the following implications:

\section{Policy}

The Polytechnic should put in place policies aimed at detecting and discouraging the menace. The following can be done:

- Guidance and Counseling Services should be made part 
of the School Curriculum (probably as part of the academic calendar/ timetable);

- Takoradi Polytechnic must insist on the admission of only qualified students (by adhering to set standards);

- The mode of examinations should be reviewed to give attention to more practical work than theory $(70 \%$ practical and $30 \%$ theory);

- The Polytechnic should come up with a policy on the proper security of examination materials.

\section{Polytechnic}

- Regular research into lurking problem of the Institution including examination malpractices should be institutionalized;

- All stakeholders within the Polytechnic must uphold the sanctity of examinations;

- Management must check and ensure that all regulations and instructions concerning the conduct of examinations (e.g. Creating a conducive envir-onment, writing of index numbers, proper identifica-tion of students and proper sitting arrangement) are carefully followed;

- There should be regular supervision of the teaching/ learning process (E.g. regular monitoring of the work schedule of Lecturers, absenteeism, late teaching, and discussion of examination questions with students etc.) by the existing chain of authority (Heads of Departments, Dean of Schools, Vice Rector among others);

\section{Research}

The study showed that factors responsible for examination malpractice significantly differed among the sexes. The research however, failed to determine the extent to which these factors differ among males and females. Further, research could be done in this area to find out the extent of influence on each sex. tly further research could be conducted into the problem of examination malpractice at other Polytechnics or Tertiary Institutions. It would be interesting to find out the degree of variance among the Institutions and how they are handled.

\section{References}

Adamu, M. (2001). "Examination Malpractice" A paper presented at the 4th Annual special and prize giving day ceremony of Federal Government College, Daura Katsina State.

Aina, O. 1991. "In Advocates of examination malpractice." www.albaspectrum. com/ articles Accessed $6^{\text {th }}$ April, 2007.

Bernard, M.O. [1998]. Examination Malpractice in Tertiary Institution in Nigeria: Types, Causes, Effects and Solution. Unpublished.

Denga, D. L. 1993. "In Advocates of examination malpractice." www. albaspectrum.com/ articles Accessed 6th April, 2007. 
Government of Ghana, "Polytechnic Law 1992", PNDC Law 321 (January 1993)

Krejcie, R.V.\& Morgan, D.W. (1970). Determining sample size for research activities. Educational \& Psycholo-gical Measurement, 30, 607-610.
Ministry of Education, Benue State 2001. "How to excel in examination and be free from cults." Makurdi, Nigeria: Ministry of Education Publica-tion

Takoradi polytechnic students' hand book (2006) 